\section{Effect of Water Vapour on the Sensitivity of a Macro-argon Ionization Detector}

As part of a comprehensive investigation into the physics of various forms of ionization detector for use in gas chromatography, it became necessary to determine the effect of water vapour on detector sensitivity. Lovelock $^{1}$ shows a graph which indicates that the sensitivity of a macro-argon detector was reduced 10 -fold by a change in water vapour concentration from about 30 p.p.m. to about 1,000 p.p.m. v/v. At less than 30 p.p.m. of water vapour, the detector response is constant ${ }^{2}$.

A steady stream of $500 \mathrm{ml} / \mathrm{min}$ of ordinary commercial argon from the British Oxygen Co. was passed through a drying train consisting of two U-tubes filled with Linde type $13 \times$ molecular sieve, in series with a further two U-tubes filled with phosphorus pentoxide. The water content of the issuing gas was certainly less than 1.5 p.p.m. v/v. The all-metal apparatus was continuously purged with this dry gas unless an experiment was in progress. Tho dry gas was thon passed into a sulphuric acid saturator which produced known concentrations of water vapour ${ }^{3}$. This wot gas was fed into a powerdriven syringe dilution system. The syringe was loaded with saturated diethyl ether vapour as the test substance. After injection of the ether vapour into the argon stream, the gas was passed into a metal ballast chamber, and thence into a flow splitter. $100 \mathrm{ml}$. $/ \mathrm{min}$ was fed into the macro-argon detector (Lovelock ${ }^{4}$ ) which was thermostatted at $50^{\circ} \mathrm{C}$. On emerging from the detector, the stream passed into an electrolytic hydrometer ${ }^{5}$, in order to measure the water vapour concentration. The ionization current signal from the Pye macro-argon detector was measured with an Ekco vibrating reed electrometer type $N 616 A$, and displayed on a Honeywell potentiometric recorder. The detector was polarized with a stabilized voltage of $800 \mathrm{~V}$ derived from a type $532 / D$ extra high tension power unit by Isotope Developments, Ltd.

Fig. 1 shows the response of the detector to various levels of ether vapour when dry argon was used. It confirms, in a general fashion, the results of Wiseman, quoted by Littlewood ${ }^{6}$. To obtain the results shown in Fig. 2, a constant test concentration of $5 \cdot 8$ p.p.m. v/v of diethyl ether vapour was used, and the concentration of water vapour varied in the argon supply. The concentration of test substance is of the same order as that of Desty, Geach and Goldup ${ }^{7}$, who used $2 \cdot 6$ p.p.m. of $n$-heptane in their evaluation of a flame ionization detector. It is seen that even a change in concentration of water vapour from 8 to 10 p.p.m. reduces the response of the detector to $5 \cdot 8$ p.p.m. of ether vapour by some 20

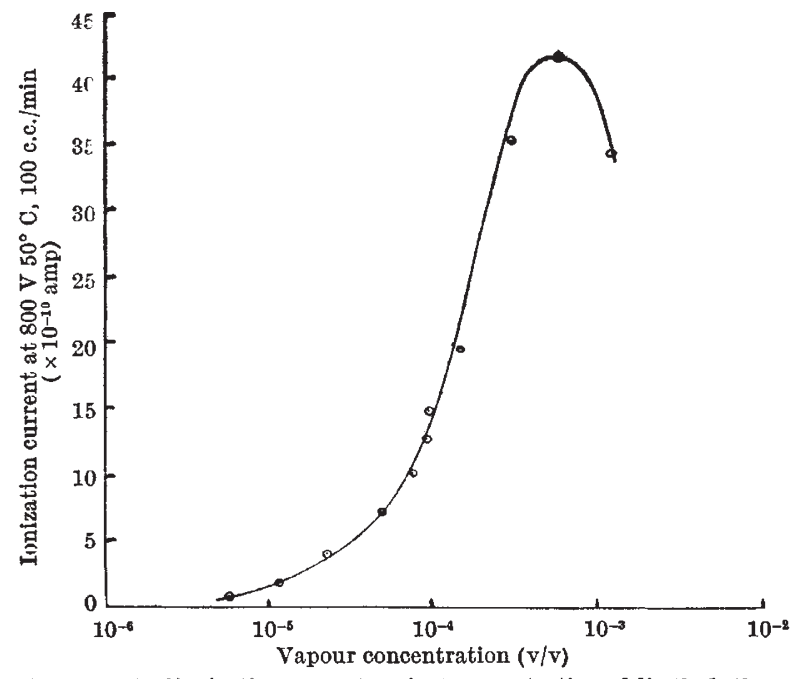

Fig. 1. Plot of ionization current against concentration of di-ethyl ether in a macro-argon detector, using dry argon

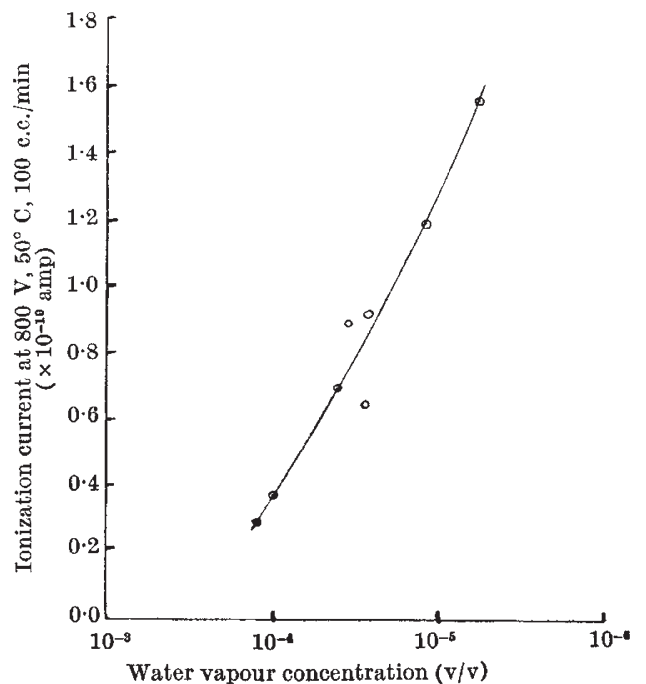

Fig. 2. The effect of various concentrations of water vapour in the argon carrier gas on the sensitivity of a macro-argon detector to a constant level of $5 \cdot 8$ p.p.m. of diethyl ether vapour

per cent. Hence it is clear that, for quantitative work, an effective drying train must be placed in the argon feed line to the detector, and the whole system thoroughly dried out as recommended by Evans and Scott ${ }^{2}$. The reduction in sensitivity is probably due to the attachment of electrons to water molecules to form negative ions having a lower mobility, Wilkinson ${ }^{8}$. Measurements were also made of the water vapour concentration in argon obtained straight from the cylinder, and Table 1 shows the results for several cylinders selected at random. With a cylinder having a pressure of $1,000 \mathrm{lb} . /$ in. $^{2}$ or more, the water concentration is likely to be of the order 3 p.p.m. This low level confirms the unpublished work of Hill in 1962 that the sensitivity of a micro-argon detector (Lovelock ${ }^{4}$ ) was not increased by placing a cold trap at $-78^{\circ} \mathrm{C}$ in the argon line.

\begin{tabular}{|c|c|c|}
\hline $\begin{array}{l}\text { Cylinder } \\
\text { No. }\end{array}$ & $\begin{array}{c}\text { Cylinder pressure } \\
\left.\text { (1b./in. }{ }^{2}\right)\end{array}$ & $\begin{array}{l}\text { Measured humidity } \\
\text { (p.p.m. v/v) }\end{array}$ \\
\hline $\begin{array}{l}1 \\
2 \\
3 \\
4 \\
4 \\
4 \\
5\end{array}$ & $\begin{array}{r}1,350 \\
880 \\
850 \\
90 \\
50 \\
27 \\
22\end{array}$ & $\begin{array}{r}2.5 \\
1.5 \\
6.0 \\
10.9 \\
15.9 \\
35.4 \\
4.5\end{array}$ \\
\hline
\end{tabular}

Even though dry argon is used, it may well be possible for the injection of a series of wet samples on to a column which holds back water vapour to give rise to a steady eluted concentration of water vapour which is sufficient to affect the detector sensitivity.

W. G. Pye, Ltd., kindly lent the detector to us, and the Hirst Research Centre of the General Electric Co. gave advice on the operation of the electrolytic hygrometer. This work was supported by the Sir Halley Stewart Trust.

$$
\text { D. W. HrLL }
$$

H. A. NEWELL

Royal College of Surgeons of England,

Research Department of Anaesthetics,

Lincolns Inn Fields, London, W.C.2.

${ }^{1}$ Lovelock, J. E. in Proc. Third Symp. Gas Chromatography, 18 (Butterworths, London, 1960).

2 Evans, R. S., and Scott, P. G. W., Nature, 190, 710 (1961).

${ }^{3}$ Crawshaw, J. K., and Davidson, H. G., J. Sei. Instrum., 36, 121 (1959).

- Lovelock, J. E., Anal. Chem., 33, 162 (1961).

s Keidel, H. A., A nal. Chem., 31,2043 (1959).

- Littlewood, A. B., Gas Chromatography, 281 (Academic Press, New York, 1962)

'Desty, D. H., Geach, C. J., and Goldup, A., in Proc. Third Symp. Gas Chromatography, 46 (Butterworths, London, 1980).

- Wilkinson, D. H., Ionization Chambers and Counters, 40 (Camb. Univ. Press, 1950). 